Linköpings Studies in Science and Technology, Thesis No. 1768

\title{
Influence of deformation and environmental degradation of Inconel 792
}

\author{
Jan-Erik Kanesund
}



Division of Engineering Materials

Department of Management and Engineering Linköping University, SE-581 83, Linköping, Sweden http://www.liu.se

Linköping, Mars 2017 
Opponent: Dr Christer Burman, Karlstad University, Sweden

Examiner: Dr Stefan Lindström, Linköping University, Sweden

Date: 13-15, March 3, 2017

Room: ACAS, Linköping University

Cover: Recrystallized grain boundary in material from an ex-serviced turbine blade, material Inconel 792.

Printed by: LiU-Tryck, Linköping, Sweden, 2017

ISBN 978-91-7685-599-7

ISSN 0280-7971

Distributed by:

Linköping University

Department of Management and Engineering

SE-581 83, Linköping

(C) 2017 Jan-Erik Kanesund 


\begin{abstract}
Industrial gas turbines are often used as a mechanical drive for pumps and compressors or in power generation as an electric power supply. The gas turbine has for many years been a popular engine due to its flexibility with respect to different types of fuel and due to a design, that enables a high power-to-weight ratio. A simplified description of a gas turbine is that the engine consists of a cold and hot section. The turbo compressor section belongs to cold section and the combustion chamber together with the turbine section belongs to the hot section. In the hot section of a gas turbine, the condition is extremely severe because of an aggressive environment characterized by high temperatures, increased temperature gradients, high pressure and centrifugal forces resulting in large stresses on individual components together with an oxidizing and corroding atmosphere. Materials used in the high temperature section (hot gas path) of a modern gas turbine are different types of superalloys, as single crystal, directionally solidified or polycrystalline alloys, depending on temperature and load conditions. In the first turbine stage, temperature is very high due to exposure to the combustion gas. To handle the problem with creep, single crystal superalloys are often used in this section. In the second row of turbine blades, the temperature of the gas is lower and polycrystalline superalloys are typically used. IN-792 is a cast polycrystalline superalloy with high strength, good resistance to hot corrosion and a cheaper option than single crystals. In the hot section of gas turbine, IN-792 is a suitable material for components such as turbine blades and vans where a complex load condition, high temperature and severe environment prevails. Due to startup and shutdown of the gas turbine engine during service, the components in the hot section are exposed to cyclic load and temperature. This will generate mechanical and thermal fatigue damage in gas turbine components. Steady state temperature gradient arises by the cooling system acting at cold spots during service to introduce tensile stress, which indirectly gives rise to creep damage in the component. This work includes tree studies of deformation and damage mechanisms of superalloy IN-792. The first study is made on test bars exposed to thermomechanical fatigue in laboratory environment, the second and the third study is made on turbine blades used during service. In the second study, the machines are placed off-shore and exposed to marine environment. In the third study the machine is landbased and exposed to an industrial environment. In the second study, the deformation and damage mechanisms are compared between the turbine blades used during service and the test bars exposed to thermomechanical fatigue testing in the first study.
\end{abstract}





\section{Acknowledgments}

This research has been funded by Linköping University, Division of Engineering Materials, Department of Management and Engineering (IEI). Siemens Industrial Turbomachinery AB has supported with test bars and turbine blades to make the deformation and damage mechanisms study.

In addition, I would like to thanks the group of skilled researchers and engineers that I have had the pleasure to work with during these past years: Håkan Brodin, Sten Johansson, Johan Moverare, Ru Lin Peng, Robert Eriksson and Bo Skoog. 



\section{Content of the thesis}

Abstract $\quad$ iii

Acknowledgement $\quad$ V

Content vii

Part I Theory and background 1

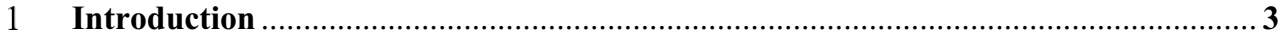



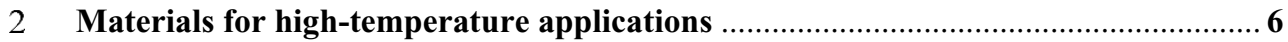

2.1 The physical properties of Ni-base superalloys .................................................... 6

2.2 Strengthening mechanisms in superalloys............................................................ 8

3 Environment degradation in the hot section of a gas turbine ................................. 9

3.1 Oxidation and High-Temperature Corrosion........................................................... 9

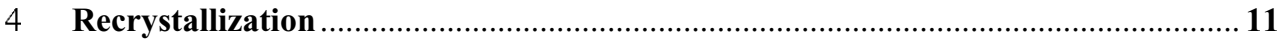

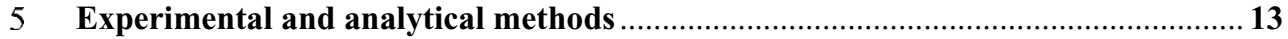



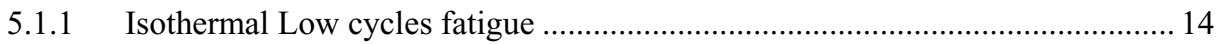



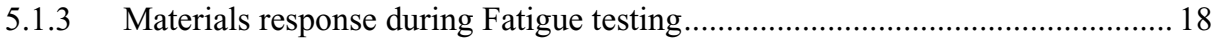

5.1.4 Materials response to Chemical degradation and Fatigue testing ..................... 19

5.2 Creep

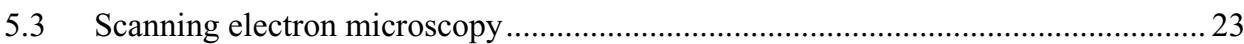

5.3.1 Electron channeling contrast imaging (ECCI) Technique ................................ 24



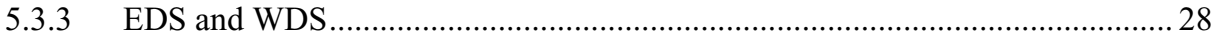

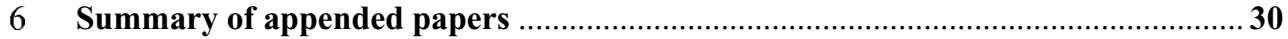


7 Conclusion

8 Outlook 34

9 References 35

\section{Part II Included papers}

Paper I: Deformation and damage mechanisms in IN-792 during thermomechanical fatigue

Paper II: Hot corrosion influence on deformation and damage mechanisms in turbine blades made of IN-792 during service

Paper III: High temperature corrosion influence on deformation and damage mechanisms in turbine blades made of IN-792 during service 


\section{Part I}

Theory and background 



\section{Introduction}

Throughout history, humans have invented machines to satisfy their needs and to help them in their daily life. A machine, which has played a specific role in power generation in this century, is the gas turbine. Today the gas turbine is used under either stationary condition (land-based, off-shore) or for propulsion (ships, aircraft). In land-based applications, gas turbines are popular because of the possibility to burn many different fuels (natural gas, diesel and kerosene, industrial by-product of chemical processes). The turbines are also reliable and have long service intervals (three to four years between major overhauls is not uncommon in cases where the turbine is on constant operation, typically $8000 \mathrm{~h}$ per year). In offshore applications, gas turbines are chosen because of the compact installation that can give a very high power output in relation to the physical size of the equipment. The same is valid for helicopter- and aero-engines, where weight must be decreased in order to generate a light design that is able to carry a high payload in order to yield highest possible economical payback. The original idea to the gas turbine has been given to the inventor John Barber that yielded a patent at the end of the 18th century [1]. George Brayton described the thermodynamic cycle of the gas turbine at the end of the 19th century and the cycle was then named after him. In the early 20th century, the first successful working gas turbine was built by Aegidius Elling from Norway and the working temperature for the machine was about $400^{\circ} \mathrm{C}[2]$.

Figure 1 shows the basic principle of a gas turbine power plant that consists of three main sections. The first one is the compressor section where air is compressed to 15 to 20 times the atmospheric pressure and at the same time, the temperature increases to $400-500^{\circ} \mathrm{C}$. The second one is the combustion and is a part of the hot section. In the burners, compressed air and injected fuel is ignited in the combustion chamber. During the combustion, a volume expansion of the gas into the blade section occurs. The temperature is thereby increased up to beyond $1300^{\circ} \mathrm{C}$. The third section is the turbine section and is another part of the hot section of the gas turbine where the hot gas is undergoing an expansion to transform to work. The Brayton cycle describes physically how a gas turbine works and the following thermodynamic processes are included in the Brayton cycle. 1-2 adiabatic compression occur in the compressor, heat addition 2-3 occurs in the combustion chamber and 3-4 adiabatic expansion occurs in the turbine. The thermal efficiency of a modern gas turbine is typically in the range from $35-40 \%$. A schematic diagram for air-standard Brayton cycle is shown in figure 2 [3].

The Brayton cycle shows if the temperature increases in step 3 (see fig. 1-2), which is the hot section of the gas turbine, the more power the gas turbine will provide. The large challenge is to design a material that can withstand a high temperature together with the complex load state present in the gas turbine Today the gas temperature in the hot section of the gas turbine can exceed $1650^{\circ} \mathrm{C}$ and the cooled part reaching temperatures as high as $1200^{\circ} \mathrm{C}$ [4]. The materials used nowadays in the hot section of the gas turbine are different types of nickel- or cobalt-based superalloys, which are the most complex of all metallic alloys designed by man. Such alloys in many cases contain more than ten alloying elements $[2,5]$. 
The blade alloys for the industrial gas turbine require some more and other properties such as longer time to creep rupture and good hot-corrosion resistance. The requirements and working conditions of aircraft engines and industrial gas turbines have changed during the years. Due to the fact that a gas turbine is required to be fully functioning for much longer periods of service, the high temperature alloys must be developed further, engine designs have to be improved and the engineering tools used for generating life assessments must incorporate accurate and reliable material behavior and material data sets. This, in turn, implies that the behavior of such materials, materials with combination of earlier mentioned properties coupled with excellent high- and low-cycle thermal fatigue resistance, must be well understood and characterized [2].

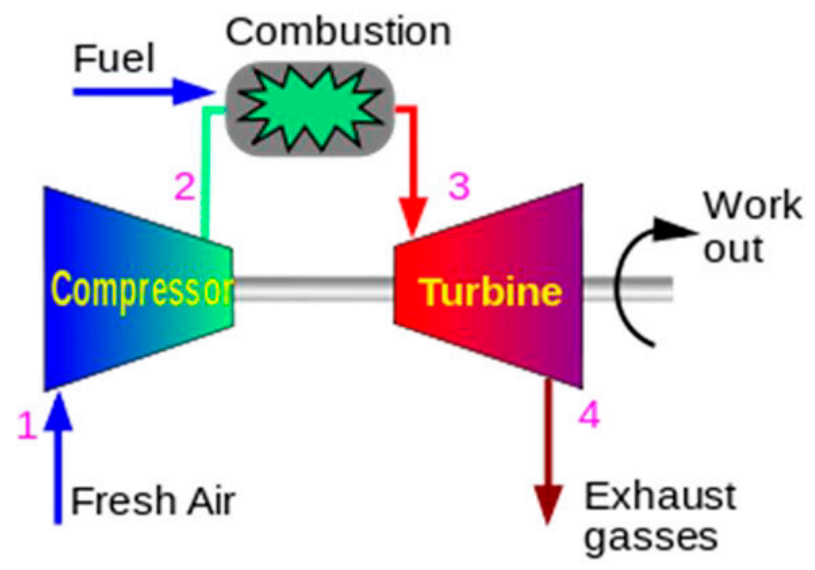

Figure 1. Schematic drawing of a single cycle gas turbine.
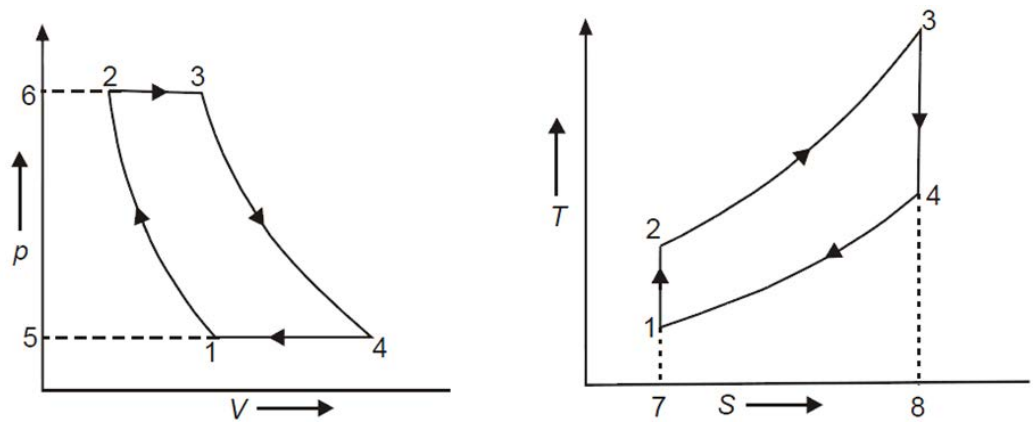

Figure 2. Description of the Brayton cycle on pressure-volume ( $\mathrm{pV}$ ) and temperature-entropy (TS) diagram, replotted from [3]. 


\subsection{Aims of the thesis}

Gas turbine blades and turbine guide vanes in the hot section of a modern gas turbine are made of precipitation strengthened nickel-based superalloys. An example of an alloy that exhibits a good balance between corrosion and oxidation resistance together with good fatigue and creep resistance is the alloy Inconel 792 (IN-792), which is a cast polycrystalline superalloy. IN-792 is a superalloy developed and patented by Special Metals Corporation. IN792 has an increased aluminum content for improved high temperature oxidation resistance while maintaining good corrosion properties.

In the hot section of a gas turbine, temperature gradients arise from startup and shut-down of the gas turbine and the cooling system. The temperature gradients will introduce thermal strain/stress on the components. The startup and shut-down will cause fatigue damage and during service the heat will cause creep damage by steady state thermal strain and stress. To simulate the cyclic thermal strains and stresses, thermal mechanical fatigue testing is used and with regard to the steady state thermal strains and stresses dwell times are often used within the fatigue cycle during the testing.

The aim of this work is to get a better understanding of the damage and deformation mechanisms of IN-792, both in specimens exposed to thermal mechanical fatigue testing and a real gas turbine blade used in service. The research focus is to investigate if thermal mechanical fatigue testing and service exposure gives the same deformation and damage mechanisms. 


\section{Materials for high-temperature applications}

The lowest common denominator for high temperature materials is that they should satisfy a number of criterions, as summarized below:

The material must have the ability to withstand loading at an operating temperature close to its melting temperature. The material need to have high creep resistance, high low cycle fatigue strength and static properties such as yield stress, ultimate tensile strength and fracture toughness, which must be maintained over the time. During the service life of a component, the materials undergoes microstructural changes due to exposure to the very aggressive environment found in the combustion gas of a gas turbine. Therefore, the material must be designed to have good resistance against oxidation, hot-corrosion and erosive wear. Materials that have been developed to satisfy these criterions are Ni-base, Co-base and Ni-Fe superalloys $[2,4,5]$.

\subsection{The physical properties of Ni-base superalloys}

The chemical composition of a Ni-base superalloy is typically very complex and an alloy can contain more than ten elements. Most of the alloying elements come from the d block of the transition metals and the behavior of each alloying element with respect to the phase stability depends highly on its position in the periodic table (see fig 3). It is important to keep the content of the tramp elements and trace elements to very small (ppm) levels in critical parts.

The matrix phase with a face centered cubic (FCC) structure is denoted (gamma) $\gamma$-phase. In IN-792, the major element in the $\gamma$-phase is $\mathrm{Ni}$ and the first class elements included in the $\gamma$ phase except for $\mathrm{Ni}$ are $\mathrm{Cr}, \mathrm{Co}, \mathrm{Ru}, \mathrm{Mo}, \mathrm{W}, \mathrm{Re}, \mathrm{Fe}, \mathrm{Ru}$ and Re. These elements stabilize the $\gamma-$ phase and a contribution to the solid solution strengthening. The most common precipitated metastable phase formed in the $\gamma$-phase is denoted (gamma prime), $\gamma^{\prime}$ and is an ordered phase, which is coherent with the matrix. The elements that promote the formation of $\gamma^{\prime}$-phase in Ni-base superalloys are $\mathrm{Al}, \mathrm{Ti}, \mathrm{Nb}$, and $\mathrm{Ta}$. These elements have larger atomic radii than $\mathrm{Ni}$ and the chemical composition of $\gamma^{\prime}$ is, depending on the alloy composition, $\mathrm{Ni} 3$ ( $\mathrm{Al}, \mathrm{Ti}, \mathrm{Nb}$, Ta). $\gamma^{\prime}$-phase is an intermetallic phase and the Ni, Co, Cr, and Mo is placed on the side of the cube and $\mathrm{Al}, \mathrm{Ti}, \mathrm{Nb}$, and $\mathrm{Ta}$ in the corner of the cube (see figure 4). The strengthening caused by the alloy additions is mainly caused by lattice misfit. Furthermore, the $\gamma$-phase dislocations need to penetrate $\gamma^{\prime}$-phase in pairs and is called super dislocations. The requirement for pairing makes it more difficult for the dislocations to penetrate the $\gamma^{\prime}$-phase, which, in turn, improves the resistance to creep deformation. The precipitates also show a unique property in showing an increase in strength with increasing temperature. Carbon, $\mathrm{C}$ is invariably present in the matrix and forms different types of MC-carbides with following element $\mathrm{Ti}$, Ta, W, Mo, Hf, and $\mathrm{M}_{23} \mathrm{C}_{6}$ with $\mathrm{Cr}$, Mo, and $\mathrm{W}$ during processing, heat treatment and service. The carbides are forming in the matrix and on grain boundaries in the $\gamma$-matrix. The carbides contribute to strengthening and to impede grain boundary sliding. Boron, B is also present in superalloys and form borides with Mo and $\mathrm{Cr}$, which reside on the $\gamma$-matrix grain boundaries. The borides are therefore very important for improved creep resistance and have the same effect as carbides in preventing grain boundary sliding. Undesirable phases can be formed in certain superalloys in service-aged conditions and a common name is topologically close- 
packed (TPC) phases and are denoted $\mu, \sigma$, Laves and etc. These phases are formed with excessive quantities $\mathrm{Cr}$, Mo W, and Re and often formed on grain boundary carbides. The formation of TCP-phase should be largely avoided since they give a loss in creep rupture life $[2,4,5]$.

\section{d-block}

\begin{tabular}{|c|c|c|c|c|c|c|c|c|c|c|}
\hline 21 & 22 & 23 & 24 & $\begin{array}{c}25 \\
\mathrm{Mn}\end{array}$ & $\begin{array}{c}26 \\
\mathrm{Fe}\end{array}$ & $\begin{array}{c}27 \\
\mathrm{Co}\end{array}$ & $\begin{array}{c}28 \\
\mathrm{Ni}\end{array}$ & $\begin{array}{c}29 \\
\mathrm{Cu}\end{array}$ & $\begin{array}{c}30 \\
\mathrm{Zn}\end{array}$ \\
\hline \hline 39 & 40 & 41 & 42 & 43 & 44 & 45 & 46 & 47 & 48 \\
$\mathrm{Yc}$ & $\mathrm{Zr}$ & $\mathrm{Nb}$ & $\mathrm{Mo}$ & $\mathrm{Tc}$ & $\mathrm{Ru}$ & $\mathrm{Rh}$ & $\mathrm{Pd}$ & $\mathrm{Ag}$ & $\mathrm{Cd}$ \\
\hline \hline 71 & 72 & 73 & 74 & 75 & 76 & 77 & 78 & 79 & 80 \\
$\mathrm{Lu}$ & $\mathrm{Hf}$ & $\mathrm{Ta}$ & $\mathrm{W}$ & $\mathrm{Re}$ & $\mathrm{Os}$ & $\mathrm{Ir}$ & $\mathrm{Pt}$ & $\mathrm{Au}$ & $\mathrm{Hg}$ \\
\hline 103 & 104 & 105 & 106 & 107 & 108 & 109 & 110 & 111 & 112 \\
$\mathrm{Lr}$ & $\mathrm{Rf}$ & $\mathrm{Db}$ & $\mathrm{Sg}$ & $\mathrm{Bh}$ & $\mathrm{Hs}$ & $\mathrm{Mt}$ & $\mathrm{Ds}$ & $\mathrm{Rg}$ & $\mathrm{Cn}$ \\
\hline
\end{tabular}

Figure 3. Part of the periodic system showing the d-block where the most of the element used in the superalloy are found.



Figure 4. Architecture of the order crystal gamma prime, $\gamma$ ' and the atoms position in the crystal. 


\subsection{Strengthening mechanisms in superalloys}

The high temperature properties depend strongly on the microstructure, which, in turn. is depending on the combination of alloying elements included in the superalloy. Some of the elements promote precipitation hardening and forms the ordered $\gamma^{\prime}$-phase, while other promote solid-solution strengthening. The ordered $\gamma^{\prime}$-phase gives contribution to strengthening, by anti-phase boundary (APB) strengthening, which is impeding dislocation motion. The size and volume fraction of $\gamma^{\prime}$-phase affect both the creep and fatigue strength of the alloy. The $\gamma^{\prime}$-phase is also involved in the anomalous yielding effect that the yield stress is increased with increasing temperature up to about $800^{\circ} \mathrm{C}$. The solid-solution strengthening is impeding dislocation motion by the stress field around the solute elements and gives a large contribution to creep strengthening $[2,4,5]$. 


\section{Environment degradation in the hot section of a gas turbine}

\subsection{Oxidation and High-Temperature Corrosion}

Oxidation is an environmental process that increases in rate with increasing temperature and occurs when metals, alloys and other materials are exposed to oxygen or oxygen containing gas. Metal oxides can form a protective scale if the oxide remains adherent and thereby prevent further oxidation. However, often the oxide has poor strength or contains large internal stresses due to rapid growth causing the oxide scale to continually spall off resulting in fresh metal being exposed to continued rapid oxidation. Oxidation can with time lead to loss of load bearing capability of the original metal or alloy component through reduction of the load carrying cross-section or by weakening the material, for instance at grain boundaries, which can result in component failure [4].

In the hot section of the gas turbine, there are other elements than oxygen that are included in the environmental induced degradation process. Sources of other deleterious elements is fuel, marine environment or industrial atmospheric pollutants. Sea water contains $\mathrm{NaCl}, \mathrm{KCl}$ and $\mathrm{Na}_{2} \mathrm{SO}_{4}$ while fuel can contain $\mathrm{H}_{2} \mathrm{~S}$ or other deleterious elements. Industrial atmospheric pollutants, which can be modified by presence of other elements, such as calcium, $\mathrm{Ca}$, chlorine, $\mathrm{Cl}$ unburned carbon, $\mathrm{C}$ and so forth. However, how these elements really affect high temperature corrosion is not wholly understood, despite that they make the high temperature corrosion extremely more aggressive. High temperature corrosion can be considered as a chemical soup, with sulfur and either sodium or potassium as necessary elements. The interplay of these environmental components with the material in different parts results in corrosion and erosion. Corrosion is chemical conversion reacting and erosion implicates mechanical impact, which lead to material loss. Erosion speed up environmental influence by removing protective oxide scales. High temperature corrosion is a phenomenon that arises when material including $\mathrm{Ni}$ and Co base superalloys is exposed to molten salts in an oxidizing gas at elevated temperature $[2,4,6,7]$. Hot corrosion is classified into two types depending on the temperature interval they are acting in. Type I hot corrosion, occurs at $800^{\circ} \mathrm{C}$ to $1000 \mathrm{C}^{\circ}$ and the corrosion processes included is basic fluxing, sulfidation or alloy-induced acidic fluxing. The process is divided in two stages and the internal stage is when the protective oxide scale breaks down. The second stage is named the propagation stage arise when unprotected metal is exposed to salts and the corrosion process proceeds with undiminished high rate $[2,4,5,8]$. Type II hot corrosion, acting in the temperature interval $650^{\circ} \mathrm{C}$ to $850 \mathrm{C}^{\circ}$ was first detected in marine applications. The corrosion processes involved are gas phase acidic fluxing or sulfidation depending on the alloy composition [2]. Other have reported pitting attack and minimal to no sulfidation [4, 5, 8]. The basic and acid fluxing are different chemical reactions between metal, gas and salts which then lead to hot corrosion $[2$, $4,5,8]$. There is another type of high temperature corrosion that can occur in the hot section of a gas turbine, especially in components made by nickel-based superalloys and becomes a part of the degradation process. This high temperature corrosion is an internal nitridation/corrosion process that occurs when a coating or protective oxide scale like chromia $\left(\mathrm{Cr}_{2} \mathrm{O}_{3}\right)$ and, alumina $\left(\mathrm{Al}_{2} \mathrm{O}_{3}\right)$ is cracked and spalled off by high mechanical and thermal stress 
or erosion. The damaged oxide scale enables nitrogen from the cooling air or combustion gas to penetrate into the base metal. The $\gamma^{\prime}$ phase contains $\mathrm{Al}$ and $\mathrm{Ti}$, which together with nitrogen form dynamically very stable nitrides such as TiN and AlN. The formation of nitrides leads to a dissolution of the $\gamma^{\prime}$ phase and a depletion zone is formed in front of the crack tip [9]. 


\section{Recrystallization}

During plastic deformation defects in the form of dislocations are created in crystalline materials, which leads to an increase in Gibbs free energy in the material, and making it thermodynamically unstable. By making subsequent heat treatments as annealing at high temperature, the Gibbs free energy will be decreased by a thermally activated process such as solid state diffusion. It provides a mechanism for defects to be removed or alternatively arranged in configuration of lower energy state and is commonly known as a recovery process. The recovery process is a metastable state and properties are only partially restored since the dislocation structure is not completely removed. After recovery, the next restoration process, called recrystallization, takes over and new dislocation free grains are established within the deformed or recovered structure. After recrystallization, new grains start to grow and grain growth takes place. These grains are then growing and consuming the old grains, which is resulting in a new grain structure with low dislocation density. During plastic deformation, particularly at high temperature, a similar softening process of recovery and recrystallization occur and these phenomena are called dynamic recovery and dynamic recrystallization. Both play important roles during creep and hot working of the material. The main difference between creep and hot working is at which strain rate they occur. Dynamic recrystallization generally begins at the old grain boundaries and the new grains are subsequently nucleated at the boundaries of the growing grains.

The $\gamma^{\prime}$-phase in IN-792 is an ordered structure $\left(\mathrm{L}_{2}\right)$ and behaves differently compared with conventional metals regarding recrystallization. The $\gamma^{\prime}$-phase $(\mathrm{Ni} 3 \mathrm{Al})$ is a strongly ordered phase where the atoms $\mathrm{Ni}$ and $\mathrm{Al}$ have different position in the lattice. These atoms are separated by a surface known as antiphase boundary (APB) and plays an important role to deformation and annealing behavior of order materials. In ordered structures, recovery and recrystallization is complicated due to the fact that several quite differently process may be occurring simultaneously in the material. Grain boundary mobility is drastically reduced in atomic ordered materials, which in turn significantly retards the recrystallization process. Weakly and strongly ordered alloys behaves differently after recrystallization with respect to APBs. The weakly ordered alloys contain APBs after recrystallization whereas strongly ordered alloys do not.

The microstructure in industrial alloys usually consists of a matrix phase and disperse second phase particles. When an alloy that contains particles is exposed to plastic deformation the particles will affect the microstructure. If the particles are sufficiently large and together with large strain, more complex dislocation structures are formed, which often involve local lattice rotation close to the particle. This region is commonly termed particle deformation zone and may affect the subsequent static annealing behavior. By enabling for the recrystallization mechanism particle stimulated nucleation of recrystallization (PSN), the grain size and texture after recrystallization is influenced. The same phenomena are observed during dynamic recrystallization, however, for particles stimulated dynamic recrystallization will only occur if the dislocations are established at the particles during deformation and is more complex than 
for PSN. Other important factors that have a large influence on the particle stimulated dynamic recrystallization occur is the temperature, large particle size and the strain rate [10].

Figure 5 shows the grain boundary from a turbine blade, which is made of polycrystalline Nibased superalloy IN-792, where probably dynamic recrystallization has occurred during service. Recrystallization studies have been performed after pre-straining and subsequent heat treatment IN-738 LC, another polycrystalline Ni-based superalloy similar to IN-792 with lower resistance to oxidation. Another study has been performed to explain dynamic recrystallization in the Ni-based superalloy Nimonic $80 \mathrm{a}$ by using a Gleeble 1500 system. The two studies show that recrystallization will take place at original grain boundaries in polycrystalline Ni-base superalloy $[11,12]$. The two studies have used higher temperature than the actual service temperature of a turbine blade. However, recrystallization temperature depends on the degree of deformation [13]. The recrystallization at the original grain boundary may also have appeared due to creep deformation in the turbine blade [10].

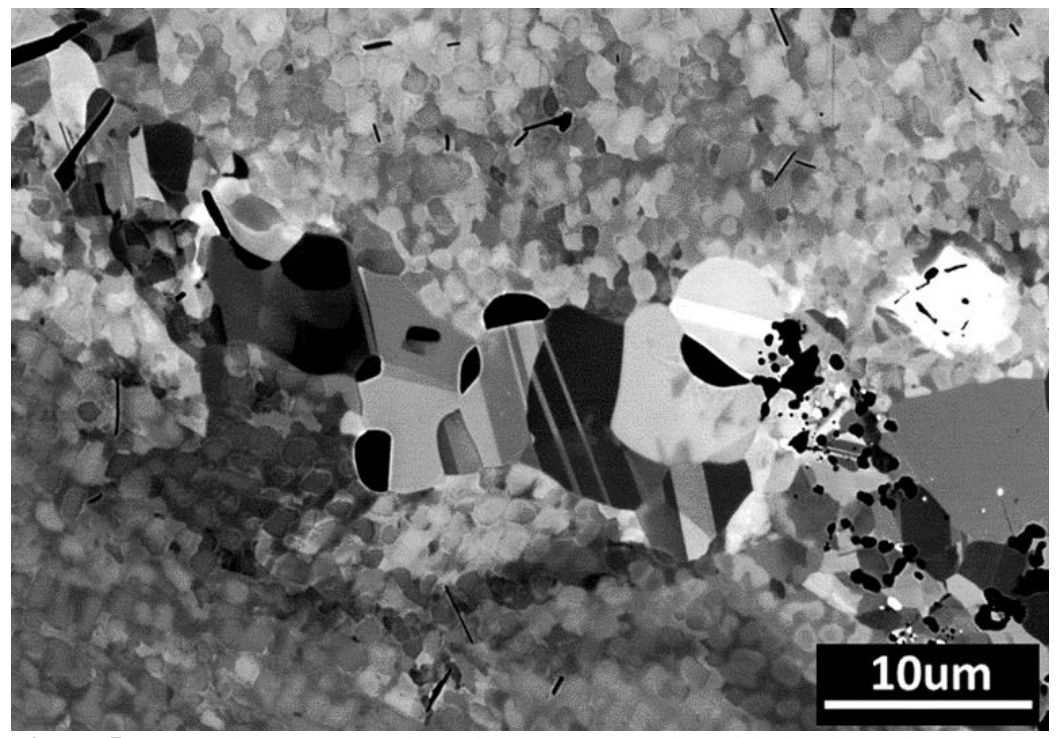

Figure 5. ECCI showing grain boundary of a gas turbine blade where dynamic recrystallization has taken place during service. 


\section{Experimental and analytical methods}

\subsection{Mechanical- and Thermal-Fatigue}

In the hot section of a gas turbine, the material is exposed to a complex load condition and high temperature. This typically induces a multiaxial stress state in the component, which, in turn, leads to damage of the components. The mechanical stress arises from pressure, mechanical end loads including centrifugal loading and constraints. Temperature differences generate temperature gradients, which in turn can induce thermal stresses from thermal strains if the area is partly or totally constrained. Temperature gradients are typically introduced from the startup and shutdown of the gas turbine, local hot and cold spots, and from gas flow heat transfer variations. Hot spots often occur on the leading and trailing edges of a turbine blade, and cold spots arise around features in the cooling system. The startup and shutdown of a gas turbine during service induce cyclic load in the components, which, in turn, generates mechanical and thermal fatigue damage $[2,14,15,16]$.

The fatigue process can be divided into low- and high cycle fatigue depending on whether the cycle load generates elastic or plastic strain. Low amplitude cyclic stress primarily provides elastic deformation in a component and is known as high-cycle fatigue (HCF). Many times, the component can be exposed to $>10^{5}$ cycles before failure, typically $10^{7}$ to $10^{9}$ cycles are chosen as a design criterion. High amplitude cyclic stress or together with stress concentration provides plastic deformation in a component, which dramatically shortens the fatigue life in the component to approximately $<10^{5}$ cycles and is denominated low-cycle fatigue $[17,18$, 19].

In the beginning, when metal alloys are exposed to cyclic loading, the material is either strain hardening or strain softening. However, with increasing number of reversals, the material will stabilize. This strain hardening or softening behavior appears to be related to the nature and stability of dislocation substructure of the material. Some materials have low dislocation density and are initially soft. However, during cycling the number of dislocations is increasing and the material exhibits a strain hardening behavior. When a material is strain softening, the material is initially a strong with large resistance to plastic deformation and the material is softening upon cycling by rearrangement of dislocations that establish new favorable substructures, which are less resistant to deformation [17].

Isothermal low cycle fatigue (LCF) and thermal mechanical fatigue (TMF) are two variants of testing methods used to characterize the material for design of components in the hot section of the gas turbine. LCF represent high amplitude low frequency plastic strain, and these large strains occur in arears where a stress concentration is present on blades and vanes. This is the case at features like holes, interior passages, curves and notches in blade attachments. LCF and TMF tests are used to simulate the contribution from mechanical strain, which appear during gas turbine start-up and shut-down. In case local thermal strain provide the largest contribution to the total stress TMF reflects the conditions on blades, vanes and around cooling system. In order to consider creep effects in the both testing methods a hold time is applied in the cycle at maximal peak strains. This generates stress relaxation and converts 
elastic strain to creep strain, which accumulates at decreasing strain rate during the hold time period $[2,14,15,16,19,20]$. Furthermore, TMF testing is also important for superalloys with coating, since these coating exhibit a ductile-to brittle transition temperature around $760^{\circ} \mathrm{C}$ [21].

\subsubsection{Isothermal Low cycles fatigue}

In isothermal low cycle fatigue (LCF) testing is performed at constant elevated temperature together with a cyclic load. The loading is applied during strain- or stress-control, however, strain controlled testing is preferred due to that the fatigue cracks start at areas where stress concentration is large. In strain controlled LCF testing, the strain amplitude is held constant during cycling. The cyclic loading produces plastic strain and form a complex stress and strain curve known as hysteresis loops. Figure 6 shows a stabilized hysteresis loop with stress relaxation that occurs when a dwell time is used during the LCF testing, where $\Delta \boldsymbol{\varepsilon}_{\mathrm{t}}, \Delta \boldsymbol{\varepsilon}_{\mathrm{p}}, \Delta \boldsymbol{\varepsilon}_{\mathbf{i}}$, and $\Delta \boldsymbol{\varepsilon}_{\mathrm{e}}$, are the total, plastic, inelastic and elastic strain ranges, respectively. $\Delta \boldsymbol{\sigma}$ is the stress range and $\mathrm{E}$ is Young's modulus [22, 23].

The Coffin Manson equation together with the isothermal LCF test were broadly used to evaluate performance of gas turbine components in the hot section of the gas turbine. However, the conditions in the hot section of the gas turbine where the temperature is cycled contribute with more damage mechanisms than the isothermal LCF testing simulates. Instead, thermal mechanical fatigue (TMF) testing provide a more realistic testing method taking into account the damage mechanisms caused the cyclic temperature [15, 24, 25].

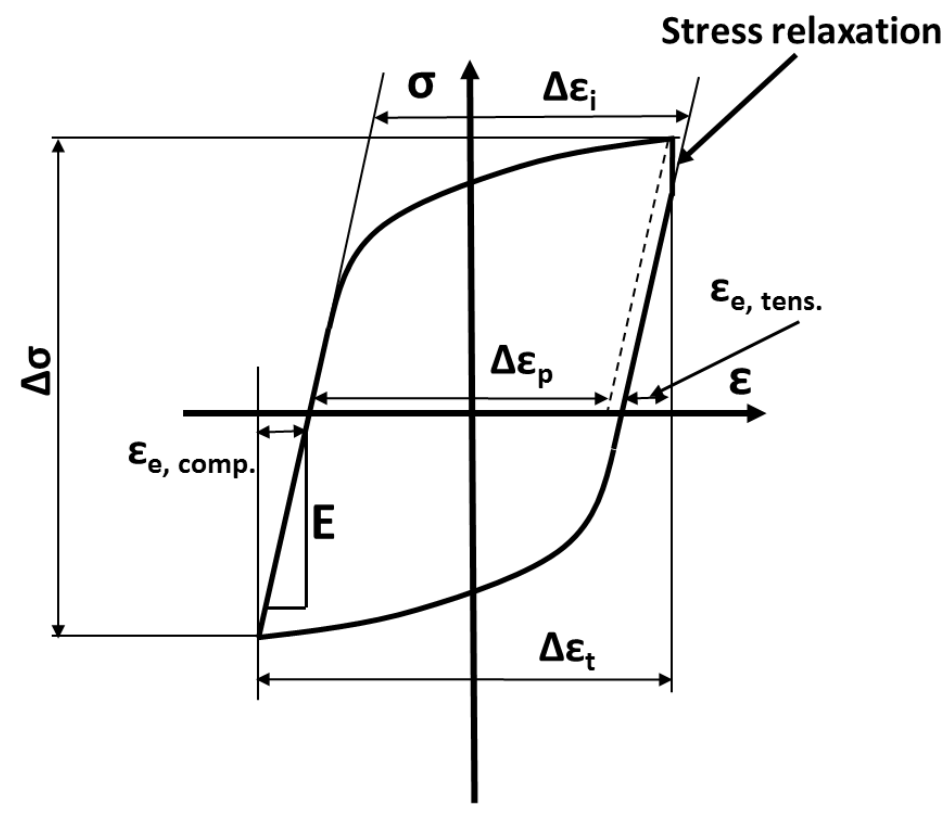

Figure 6. Showing stable hysteresis loop with dwell time during strain controlled LCF testing. 


\subsubsection{Thermal mechanical fatigue (TMF)}

Thermomechanical fatigue (TMF) is performed by cycling the temperature and load simultaneously. The relation between when the load- and temperature cycles reach their maximum and minimum levels is designated as a phase shift, $\theta$. The phase shift can be changed to any desired value $0<\theta<180$. In common testing practice, a tradition has been established where a few extremes are typically evaluated and the two essential types of TMF cycles are in-phase (IP) and out-of-phase (OP) TMF testing.

In an IP-cycle $\left(\theta=0^{\circ}\right)$, the maximum value of temperature and mechanical strain or stress occur at same time. An IP cycle is a simulation of a cold spot in a hot environment, which in turn led to tensile stress or strain in the component due to the temperature different that generating a temperature gradient. Furthermore, the centrifugal loads acting on a turbine blade in operation is best described by IP TMF testing. An IP-cycle with dwell time is necessary for a good representation of the situation in a land-based gas turbine, where the turbine can be operating at constant temperature for weeks to months, dwell time can be suitable to in a correct manner simulate the circumstance arising around the cooling system in a turbine blade and vane during service.

In an OP-cycle $\left(\theta=180^{\circ}\right)$, the maximum value of the temperature and mechanical strain is out of phase with one half cycle. OP-cycle is a correct simulation of a hot spot in cold environment, which in turn led to compression stress or strain in the component as in the IPcycle gives rise to a temperature gradient. An OP-cycle is suitable to simulate the condition advised on the leading and trailing edges of a turbine blade.

TMF testing is performed either by a stress or strain controlled approach, depending on which of the loads that dominate in a certain area of the component. If mechanical loads, which arises from centrifugal force during service, is dominating in an area of the component, stress controlled approach is suitable to use during testing (see figure 7 at A). However, if instead, a thermal load arises due to a temperature gradient during service, a strain controlled approach is more suitable (see figure 7 at $\mathrm{B}$ ). This is the dominating mechanism, in for instance, an area of the component as at leading and trailing edges, and cooling system of the turbine blade, TMF testing takes in account most of the damage mechanisms that occur in the component in the hot section of the gas turbine due to variations in loads and temperature. The three most significant mechanisms are fatigue (mechanical cyclic load), creep and environment (oxidation/corrosion). These three damage mechanisms have large influence on fatigue life of the component. The damage mechanisms can work together and cause damage, however, one of them can be dominating and give the largest contribution to component failure [14, 16, 22, $24,26,27,28]$. 


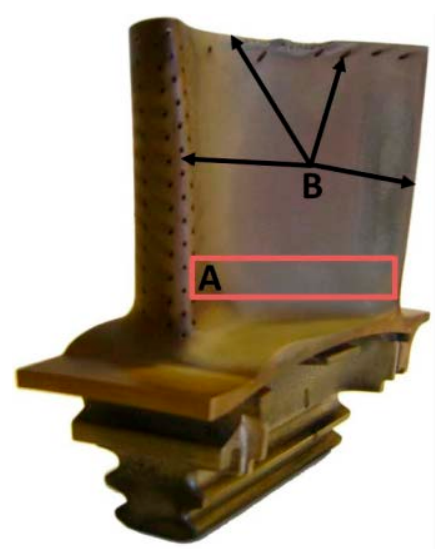

Figure 7. Ex-serviced gas turbine blade where environmental and fatigue damage has occurred. Strain or stress controlled testing is performed in life assessment of the blade.

The stabilized stress and strain TMF-cycle's hysteresis loops for IP and OP cycle are shown in Figure 8 a) and b), respectively. In the hot end of the both cycles, stress relaxation occurs due to the dwell time imposed in the hot end of the cycle during the testing. In the cold end of the cycle, plastic deformation occurs during testing. The $\Delta \boldsymbol{\varepsilon}_{\text {in }}$ inelastic strain and $\Delta \boldsymbol{\sigma}$ as the total stress range is shown in the figure 8 a) and $b$ ). Turbine blade materials as Ni-based superalloys can withstand only low inelastic strains, which gives the stress-strain hysteresis loop a characteristic narrow appearance.

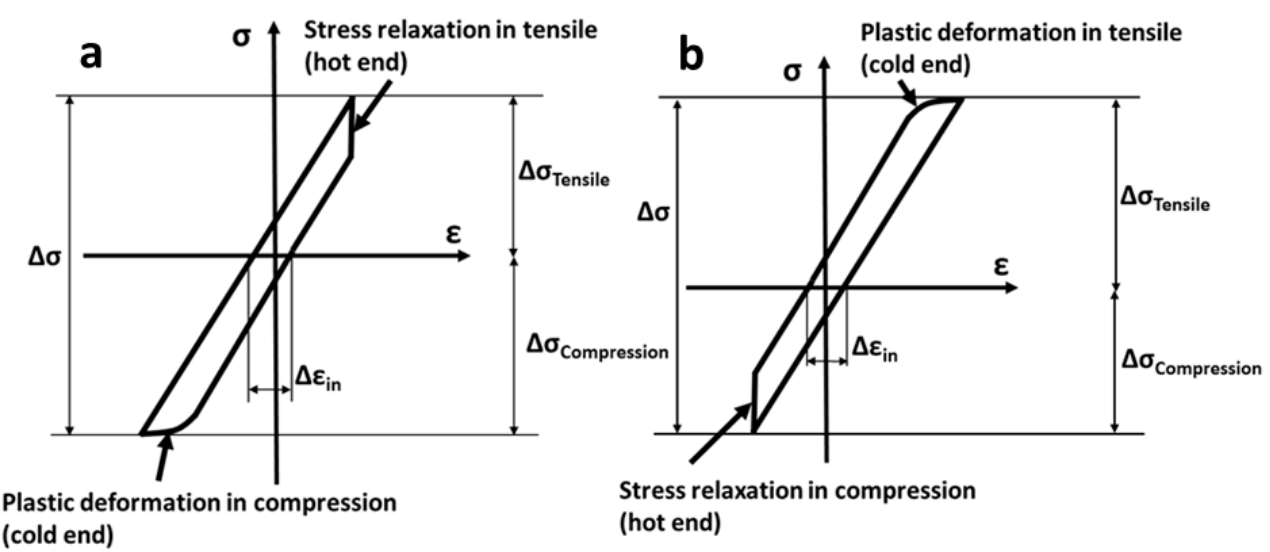

Figure 8. Typical stable hysteresis loops with dwell time during strain controlled TMF testing a) inphase (IP) cycle and b) out-of-phase (OP) cycle. 
The variation of thermal, mechanical and the total strain during time for IP and OP cycles, respectively is shown in Figures 9 to 10 . The mechanical strain, Emech is the sum of the elastic, $\boldsymbol{\varepsilon}_{\mathrm{el}}$ and inelastic strain, $\boldsymbol{\varepsilon}_{\mathrm{in}}$ and the total strain, $\boldsymbol{\varepsilon}_{\mathrm{tot}}$ is the sum of thermal strain, $\boldsymbol{\varepsilon}_{\mathrm{th}}$ and mechanical strain, Emech, Eqn (2).

$$
\begin{aligned}
& \varepsilon_{\text {tot }}=\varepsilon_{t h}+\varepsilon_{\text {mech }}=\alpha\left(T-T_{0}\right)+\varepsilon_{e l}+\varepsilon_{\text {in }} \\
& \varepsilon_{\text {mech }}=\varepsilon_{\text {tot }}-\varepsilon_{t h}
\end{aligned}
$$

where, $\mathrm{T}_{0}$ is the reference temperature where the test beginning, $\mathrm{T}$ is the test temperature and $\boldsymbol{\alpha}$ is the coefficient of thermal expansion. In the TMF test, only the total strain can be measured. A calibration cycle is performed to yield the thermal strain as a function of temperature or time. After this, the thermal strain, $\boldsymbol{\varepsilon}_{\mathrm{e}}$ is subtracted from total strain, $\boldsymbol{\varepsilon}_{\text {tot }}$ to obtain the mechanical strain, $\boldsymbol{\varepsilon}$ mech according to Eqn (3). The test is controlled on mechanical strain through subtracting thermal strain from total strain according to Eqn (3) [14, 22, 29, 30].

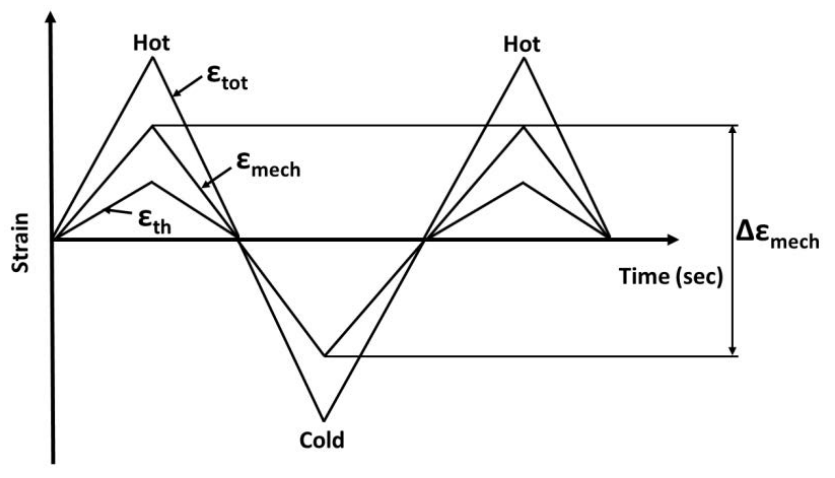

Figure 9. Variation of thermal, mechanical and total strain during an in-phase cycle.

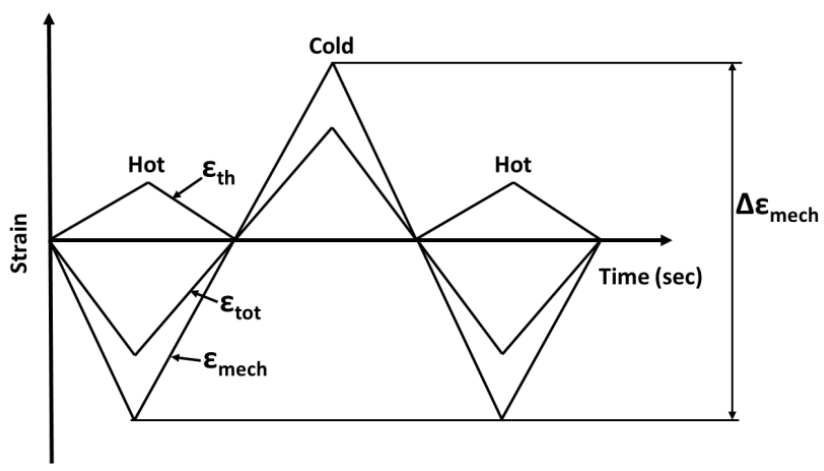

Figure 10. Variation of thermal, mechanical and total strain during an out-of-phase cycle. 


\subsubsection{Materials response during Fatigue testing}

Material studies have been performed on cast polycrystalline Ni- based superalloy IN738CL, IN-792 CC, C-1023, M936, K417, CTD-11 and IN-792. These types of materials are use in turbine blades and vanes and have large grains to minimize the number of grain. The testing methods used in the studies are TMF-testing with IP and OP cycles and isothermal LCF. The most important factors which indirect influence fatigue life and damage mechanisms during the testing are the temperature, the mechanical strain range and which type of material used in the fatigue study. In the studies, where IP-testing has been performed and if the temperature and mechanical strain is sufficiently high the dominating damage mechanism for IP-testing is creep damage due to the cracks are propagating intercrystalline in the material. In the same studies, it is reported that mechanical fatigue is dominating damage mechanism for OP testing due to the cracks are propagating transcrystalline and many fatigue striations are visible in the fracture surface. Another important damage mechanism for OP-testing is oxidation which has a major impact on the fatigue life. It is also reported that mixed crack propagating can occur in IP and OP testing, where both intercrystalline and transcrystalline occur. In some of the studies, both TMF-testing and isothermal fatigue testing are performed to evaluate the fatigue life. Both IP and OP testing have lower fatigue life compared to isothermal LCF and regarding IP and OP so have IP-testing lower fatigue life than OP-testing, However, there is a crossover when the strain is below $0.4 \%$ the OP-testing obtain longer fatigue life than IPtesting. In the studies, where dwell time is used in the IP-testing the fatigue life drastically decrease due to stress relaxation occur and increasing the contribution of creep damage in the testing [14, 22, 24, 26, 27, 29, 31, 32]. 


\subsubsection{Materials response to Chemical degradation and Fatigue testing}

The fatigue testing mentioned in section 5.1.3 is performed in air, which result in an environment damage mechanism caused by oxidation. However, in the hot section of the gas turbine, there may be other deleterious elements present such as sulfur, sodium, calcium, potassium, chlorine, unburned carbon and $\mathrm{C}$. The sources of these elements is fuel $\left(\mathrm{H}_{2} \mathrm{~S}\right)$, marine environment such as sea water $\left(\mathrm{NaCl}, \mathrm{Na}_{2} \mathrm{SO}_{4}, \mathrm{KCl}\right)$ or industrial atmospheric pollutants (calcium, chlorine, unburned carbon, C). Sulfur compounds together with high temperature are responsible for the phenomenon called hot corrosion. Sulfur penetrates deep into the grain boundaries by forming sulfides (sulfidation, type I hot corrosion) that are oxidizing. Released sulfur diffuses deeper into the metal or grain boundaries where sulfides are formed. This process is autocatalytic. Sulfur is extremely deleterious to the grain boundaries by making them brittle, which lead to a shortened creep and fatigue life of components as reported by many authors [7, 33, 34, 35, 36, 37]. Hot corrosion is influenced by a threshold stress hold level, which depending on alloy, makes the rupture life insensitive to hot corrosion [7, 36]. In case, the components are made of precipitate hardened nickelbased superalloys by formation of $\gamma^{\prime}$ phase the phenomenon internal nitridation/corrosion may occur. High mechanical and thermal stress, that originates from creep or fatigue loading and superimposed thermal loading, enable spalling and cracking of the proactive oxide scale. This enables nitrogen from the cooling air or combustion gas to penetrate into the base metal of the components in the hot section of the gas turbine. The nitrogen can react with $\mathrm{Al}$ and $\mathrm{Ti}$, which form dynamically very stable nitrides such as TiN and AIN. The formation of nitrides leads to dissolution of $\gamma^{\prime}$ phase and depletion zone can be formed in front of the crack tip [9]. 


\subsection{Creep}

At room temperature, the material is deformed by slip or twinning or both, however, at higher temperatures a new deformation mechanism arises known as creep. The activation temperature where creep begins is about $\mathrm{T}>0.3$ to $0.4 \mathrm{Tm}$, where $\mathrm{T}_{\mathrm{m}}$ is the melting temperature of the metal. In creep deformation, there are several models presented to describe deformation mechanisms including dependence of stress and temperature levels. NabarroHerring and Coble creep are two creep mechanisms that occur at low stresses and high temperature. Nabarro-Herring creep involves atomic and vacancy bulk diffusion and Coble creep involves atom or ion diffusion along grain boundaries (see figure 11). At temperatures, higher than $0.5 \mathrm{~T}_{\mathrm{m}}$ and intermediate to high stress levels, the creep deformation is thought to be controlled by diffusion controlled movement of dislocations where edge dislocation climb is involved. Grain-boundary sliding is another deformation mechanism that occur at hightemperature being a complex deformation mechanism where shear-induced displacement, Nabarro-Herring or Coble process, and dislocation climb are interacting [17,38].

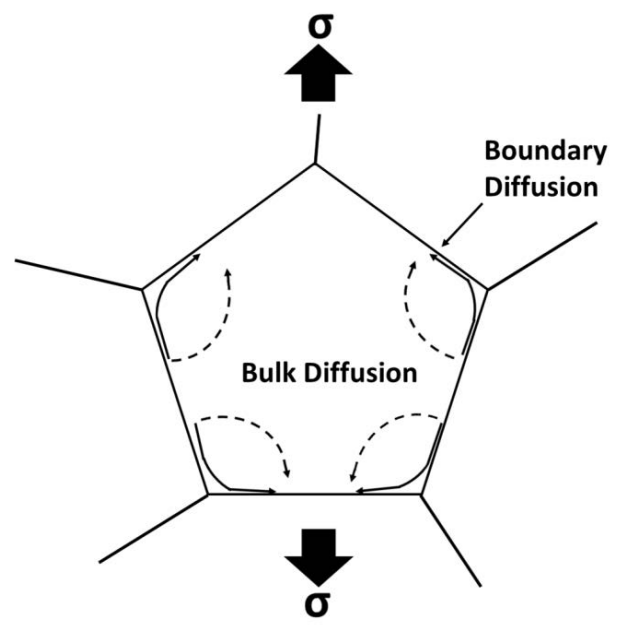

Figure 11. Two different creep mechanisms are considered in a polycrystalline superalloy. The, solid line represents Coble creep, and the dashed line Nabarro-Herring creep.

Creep tests are performed by applying a constant tension or compression load to a test bar at constant temperature in a hot furnace. Figure 12 shows a characteristic engineering creep curve obtained by plotting strain vs. time. The creep curve is divided in three sections, and the first section is primary creep, the second is steady-state creep and the third is tertiary creep leading to failure. The changes in creep response is believed to depend on interaction between a strain hardening and a recovery process, which in turn highly influence the total strain rate of the material at a given temperature and stress. It is believed that strain hardening at elevated temperature includes subgrain formation associated with rearrangement of dislocations and that the recovery process is dominated by thermally activated cross-slip and edge dislocation climb. The conclusion that can be made is that the decrease in strain rate in primary creep to steady-state creep must depend on changes in substructure, which is unfavorable to dislocation motion. The constant strain rate in steady-state indicates that the 
substructure is stable and that there exists a dynamic balance between hardening and softening. In the tertiary creep, the creep strain rate is accelerating and balance between hardening and softening is lost and is dominated by a number of weakening metallurgical instabilities. Some of the microstructural changes are localized necking, corrosion, intercrystalline fracture and, formation of micro voids. In addition, recrystallization of strainhardened grains may occur, which further destroy the balance between the hardening and softening [17, 38].

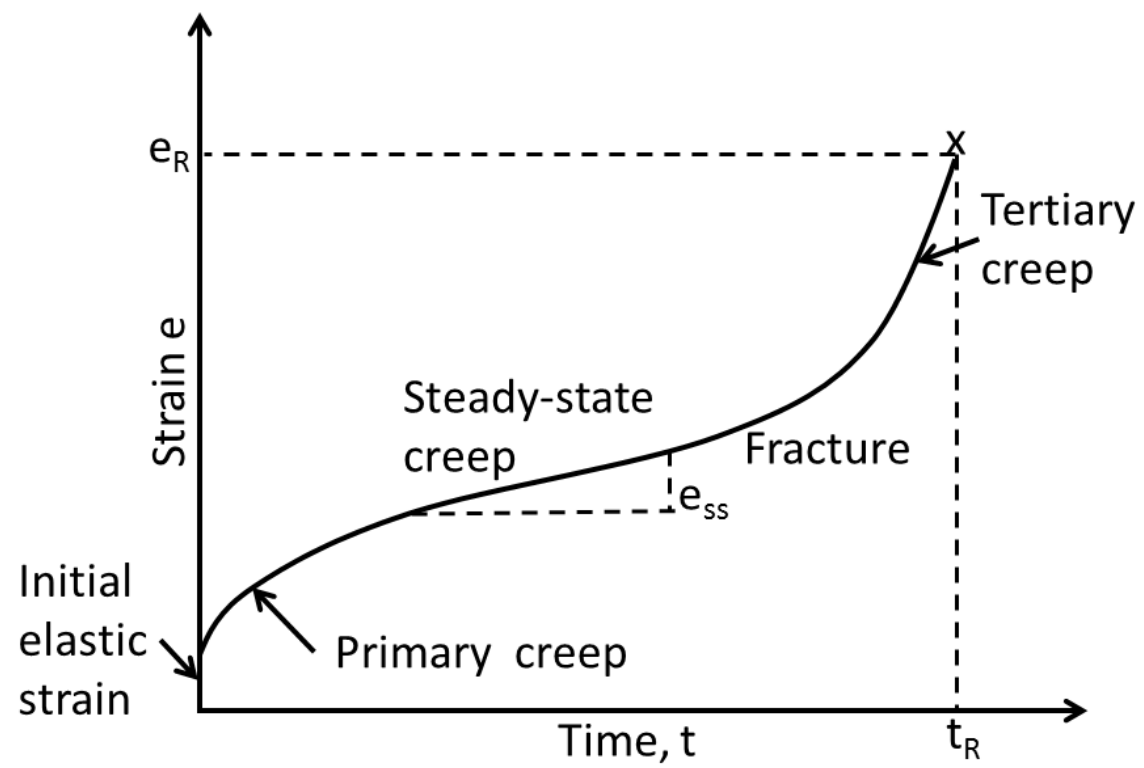

Figure 12. Schematic drawing of an engineering creep curve and the different stages which occurr during the testing of the material.

Creep damage in polycrystalline materials involves intergranular crack propagation, a combination of grain boundary sliding (GBS) and grain boundary cavitation, which is associated with stress concentrations or structural irregularities such as grain boundary ledges, triple points. The stress level has large influence if grain boundary sliding occurs, which is promoted by high temperature and low stress level i.e. low strain rate. If neither diffusional mass transport or intergranular plastic flow is possible, grain boundary decohesion is taking place by formation of a planer array of grain boundary cavities [17].

Figure 13 shows a typical creep damages where intercrystalline crack propagating, cavitation and particle decohesion is included and the damage has arisen during service in a gas turbine. 


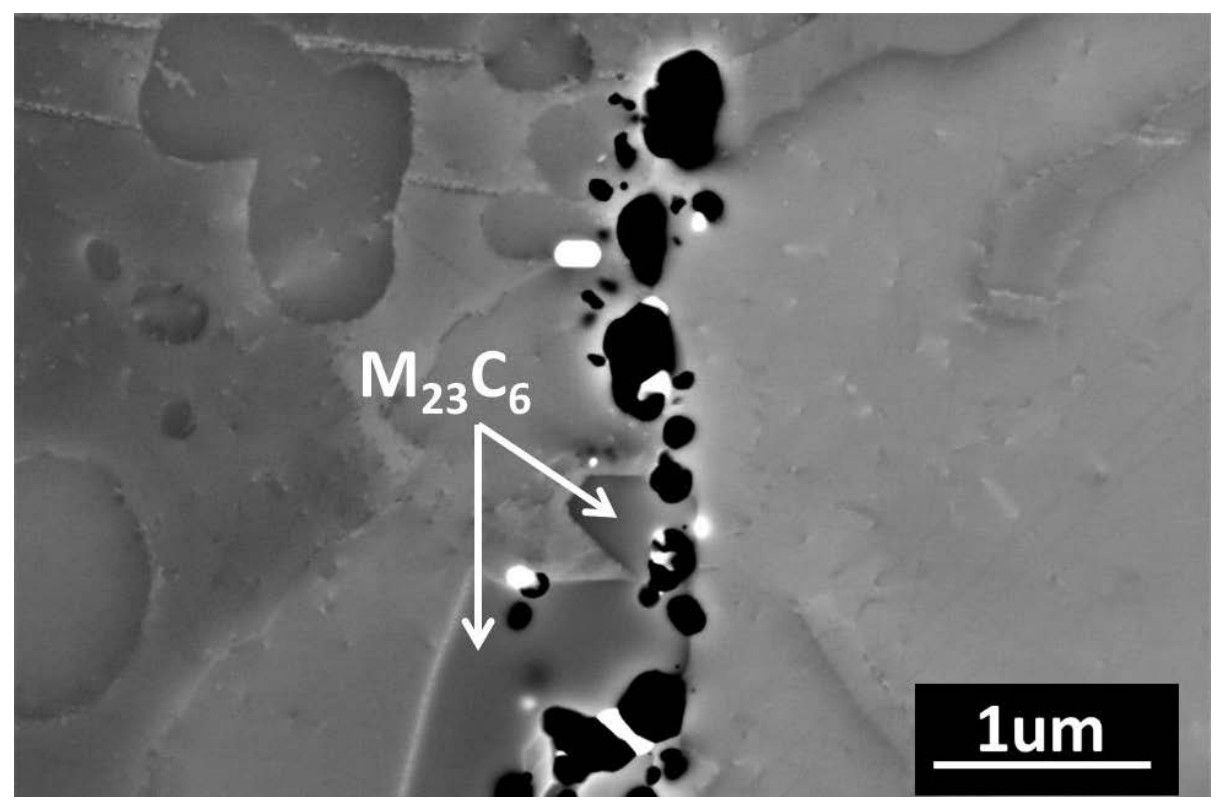

Figure 13. ECCI showing creep damage arisen during service in a gas turbine blade. 


\subsection{Scanning electron microscopy}

The damage mechanisms that arise from mechanical and thermal fatigue is studied on cut and polished cross-sections of tested or gas turbine exposed material by field emission gun scanning electron microscopy (FEG-SEM) in a microscope equipped with different image and analytical detectors. The image detector used in the present study is an angular selective BSE detection system (ASB detector) that is a special type of backscatter detector to obtain electron channeling contrast imaging (ECCI) and compositional contrast. The analytical detectors used in the study are electron back scattering diffraction (EDSD) and to X-ray analysis energy dispersive spectrometer (EDS) and wavelength dispersive spectrometer (WDS). Figure 14 is showing the most of the detectors used in this study and in the same time the figure shows the EBSD experimental setup.

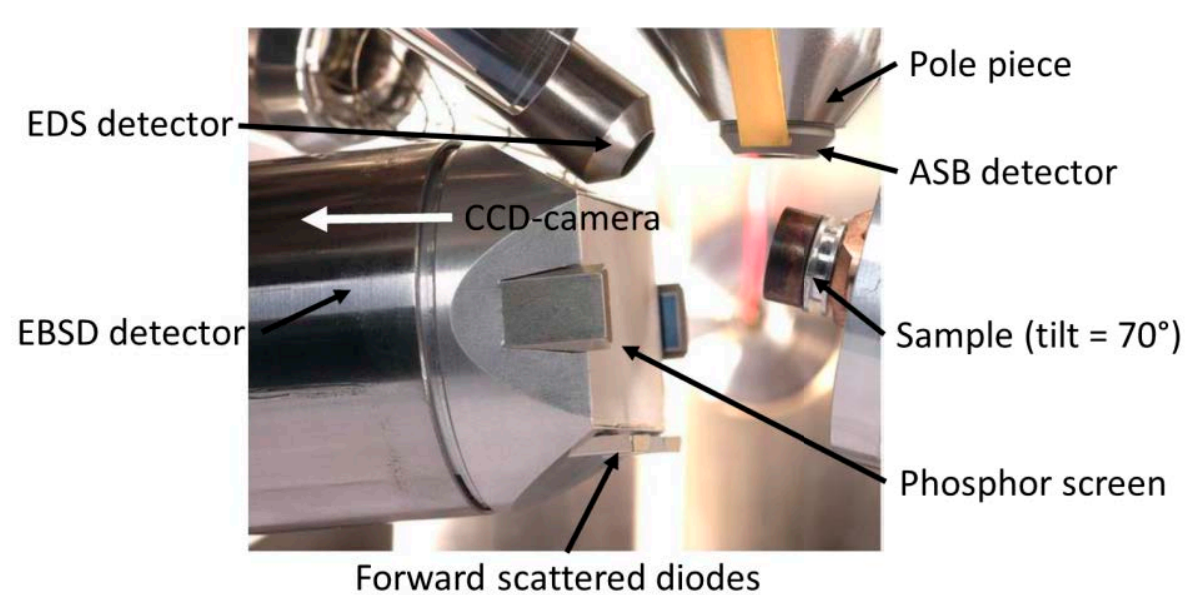

Figure 14. Image showing an EBSD experimental setup and other detectors that typically are present in a FEG-SEM chamber. 


\subsubsection{Electron channeling contrast imaging (ECCI) Technique}

The angular selective BSE detection system is designed to select backscatter electrons (BSE) with large and very large scattering angle, which come from different scattering processes. The definition of the angle mentioned as scattering angle is somewhat confusing depending on the reference being used. If the scattering angle is counted from the incident beam as angle $\beta$, the scattering angle will become large. If the angle instead is counted from the sample as angle, $\theta$, which is the takeoff angle, the scattering angle will instead become low. In the current work, a Zeiss microscope is used and here Zeiss uses angle $\beta$ as scattering angle (see figure 15). The ASB-detector shows channeling contrast (crystal orienteering) and compositional contrast (Z-contrast) by separating different types of BSE electrons that is established through multiple inelastic (Z-contrast) and single elastic (crystallographic contrast) scattering mechanisms. Multiple inelastic scattering is minimized to increase the sharpness in the image [39]. Electron scattering mechanisms related to electron backscatter and channeling are Bragg scattering, phonon scattering or thermal diffuse scattering (TDS), core loss scattering and multiple scattering where chain of scattering events has occurred that including inelastic and phonon scattering [40]. By using ECCI technique crystallographic defects, which produces a distortion in the lattice, such as dislocation or substructure, twins, stacking faults and grain boundaries are possible to observe (see figure 16). ECCI technique produces images that are similar in appearance to transmission electron micrographs, however, with lower resolution [41]. The reason to use accelerating voltages below the commonly used value of $20 \mathrm{kV}$ is that with decreasing voltage the cross section for phonon scattering is increased, which led to that bright parts in the image, i.e. dislocations, appear brighter while the dark parts maintain their low intensity. A smaller interaction volume gives also better channeling contras, which in turn give features as dislocations appear more shaper in the image [42]. The acceleration voltage used in the study is $10 \mathrm{KV}$ or lower to obtain good ECCI.

\section{Incident electron beam}

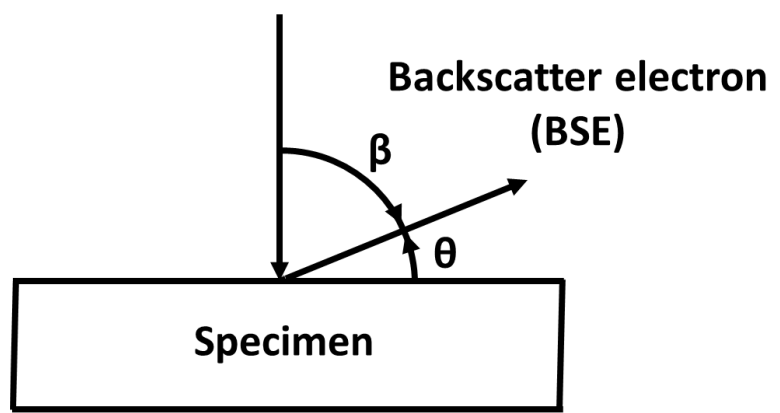

Figure 15. Definition of takeoff angle, $\theta$ counted from the surface and the angle, $\beta$ counted from the beam. 


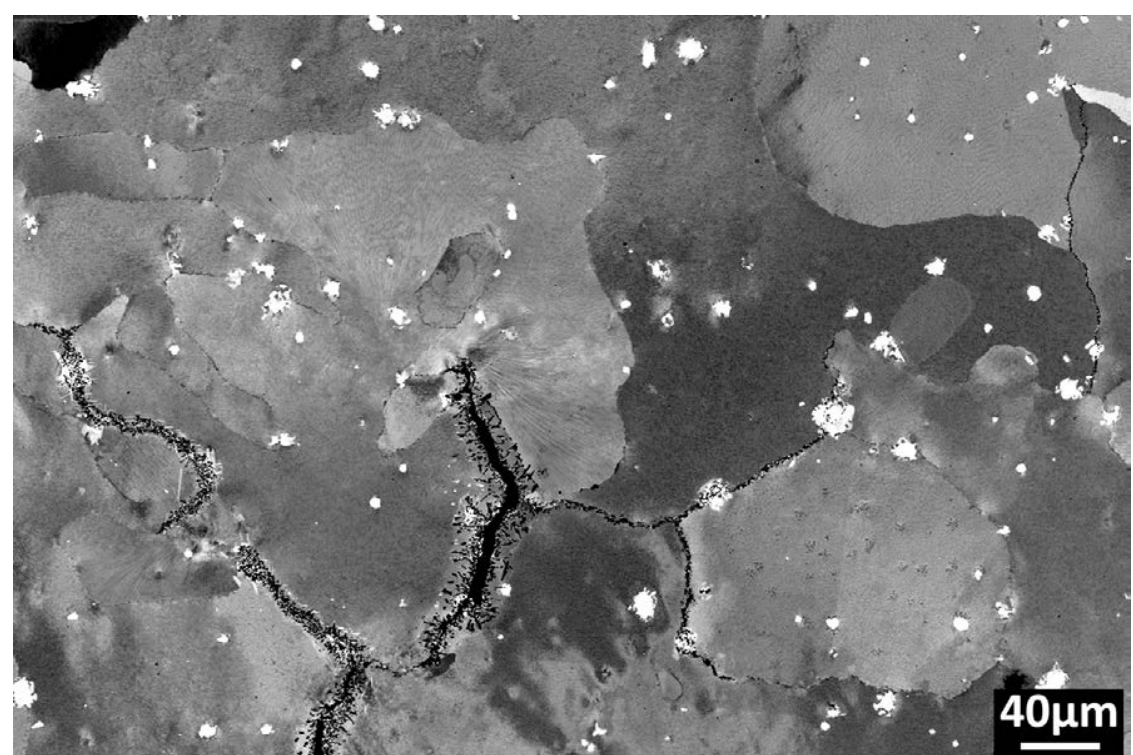

Figure 16. ECCI showing where different grains and substructures (contrast different) inside grains are visible. In the same micrograph, creep and hot corrosion damage is visible in the grain boundaries. 


\subsubsection{EBSD Analysis}

Electron backscatter diffraction is a SEM based technique to obtain crystallographic information about the microstructure. Typical EBSD measurements for microstructural characterization are orientation and misorientation relationships between grains/phase, grain size, texture, recrystallization, twins and etc.

Figure 17 shows the basic system components included to perform EBSD.

- A crystalline sample tilted $70^{\circ}$

- EBSD detector with phosphor screen and forward scatter diodes

- The phosphor screen is fluoresced by electron scattering.

- A charge couple device (CCD) base camera together with optics for displaying the pattern formed on the phosphor screen.

The principal technique to obtain crystallographic information by using EBSD is that a stationary electron beam interacts with a crystalline sample tilted 70 . Figure 17 a) show a diffraction cones, which is generated of electrons that satisfy Braggs law and are diffracted form a given single lattice plan (hkl). The cones are projected on the phosphor screen and establish the Kikuchi bands that are visible in the electron backscattered diffraction pattern (EBSP) (see fig 17 b)). The crystal orientation is found by using Hough transformation of the original diffraction pattern so that the diffraction pattern can be indexed. The EBSP is characteristic of the crystal structure and orientation in the sample region where is generated [43].
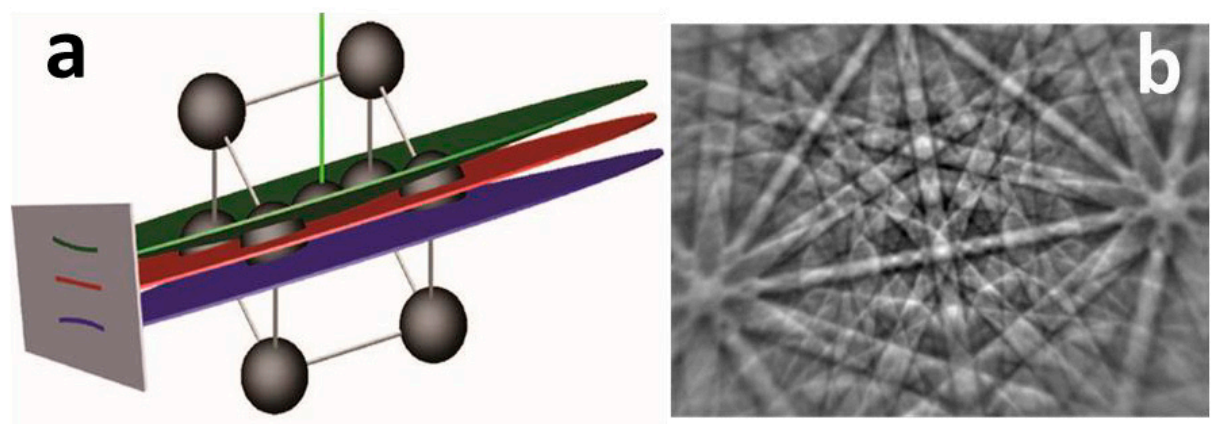

Figure 17. Visualization of a) diffraction cones established from a given single lattice plan (hkl) and b) electron backscattered diffraction pattern (EBSP), replotted from [43].

The EBSD data is processed in a post processing program known as Channel 5. The program consists of different program modules and one of the program module is Tango. In Tango, orientation maps and misorientation profile can be established. Orientation maps shows different crystal orientations in different colors and the black line shows high angle grain boundaries (see figure $18 \mathrm{a}$ )). Figure $18 \mathrm{~b}$ ) shows a misorientation profile shown high angle grain boundaries in the Y-direction in figure 18 a). Orientation maps and misorientation 
profile allows you to detect whether recrystallization has occurred in an area as in figure 5 in chapter 4 .
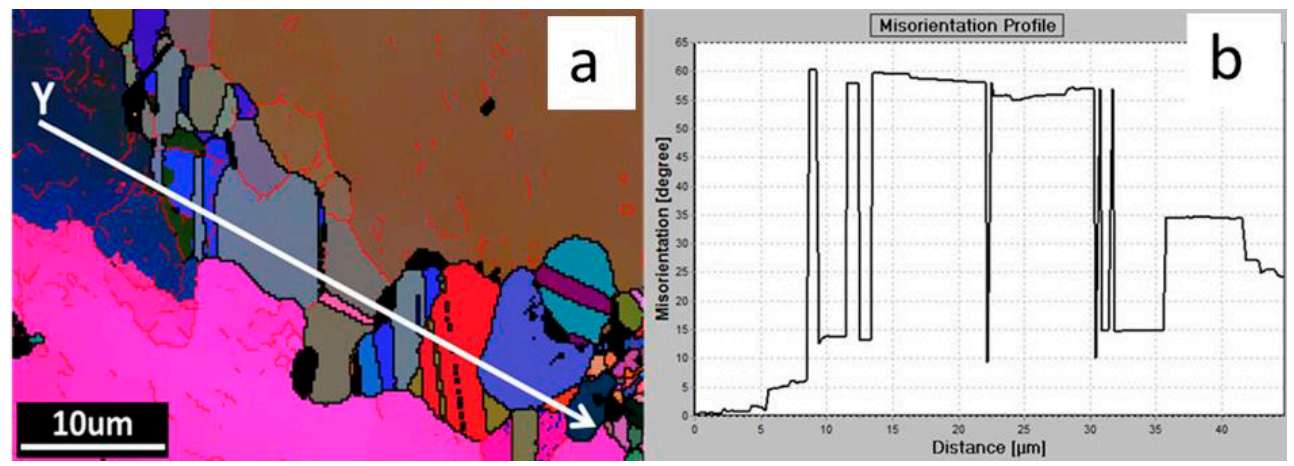

Figure 18. Example of results from electron backscatter diffraction measurements where a) is an EBSD orientation-map and $b$ ) is a misorientation profile along arrow Y orientation-map in figure a). 


\subsubsection{EDS and WDS}

When a high energy electron beam from a scanning electron microscopy (SEM) interacts with a sample an interaction volume is formed below the surface of the sample. In a part of the interaction volume, characteristic X-ray is established from the elements that is included to the sample (see figure 19 a). A simple description of an atom is that the atom has a core and orbital electrons, which are placed on specific electron shells. The three firsts electron shells are denoted $\mathrm{K}, \mathrm{L}$ and $\mathrm{M}$ where $\mathrm{L}$ and $\mathrm{M}$ is divided into several subshells. A photon is emitted when an electron from an electron beam strike out an electron placed on an electron shell and an electron from an outer electron shells jumps down and take its place. The characteristic Xray is measured either with regard to energy or the wavelength of the photon. Detectors used to measure the characteristic X-ray are energy dispersive spectrometers (EDS) and wavelength dispersive spectrometers (WDS). The elements available in a sample is shown in $\mathrm{X}$-ray spectrum where an element shows its peaks. An element can have one or several peaks depending on how many interior electron shells that belong to the element. Generally, $\alpha$-peak arises when an electron jumps down from L-shell to K-shell and $\beta$-peak arises when an electron jumps down from M-shell to K-shell (see figure $19 \mathrm{~b}$ ). The EDS peaks have lower resolution compared to the WDS peaks i.e. the EDS peaks are broader than WDS peaks and this creates problems when two or more elements have nearly the same energy so the peaks are overlapping each other [44]. In order to overcome this problem, with overlapping peaks, WDS is used instead. When analyzed in terms of wavelength, the peaks are more narrow and are therefore more easily separated. However, to day, Oxford instrument has developed Tru-Q data processing technology that is a new technic to handle the problem with overlapping peaks in an EDS analysis. Tru-Q is using filtered least squares fitting (FLS) and complete hardware chain characterization (QCAL). FLS is an algorithm for removing X-ray background from the spectrum and fitting peaks profiles of the identified elements to calculate peak areas [44]. QCAL is use to determining the precise position, resolution and shape of all element peak profiles. This implies that peak area and intensity relative to that of pure element may be calculated to a new level of accuracy. TruMap (EDS) uses Tru- Q data processing technology to solve the problem with overlapping x-ray peaks [46, 47]. To confirm that TruMap really can solve the problem with two elements overlapping each other a test was performed to identify Molybdenum and sulfur. TruMap, which use EDS to obtain the x-ray data, and WDS map has been performed over a grain boundary where sulfides have been formed in it and there is molydelium in the matrix of the material. Molybdenum and sulfur are two x-ray peaks that overlap each other and the result from the WDS and EDS maps are shown in the two figures 20 to 21, respectively. By studying the figures, it is clearly shown that the two maps for sulfur have nearly the same appearance and the two maps for molybdenum differ totally compared with the two sulfur maps. The shape of the most original peaks is included in Aztec, which is to great help to solve the problem with overlapping peaks by comparing original peaks and the spectrum peak. The excitation energy for a specific elements peak should be three times the peaks energy, which in turn give that an acceleration voltage of $20 \mathrm{KV}$ is used in the most cases. 



Figure 19. Figure showing a) interaction volume of the electron beam and where the characteristic $X$ ray emitted and, b) EDS spectrum with different iron peaks.

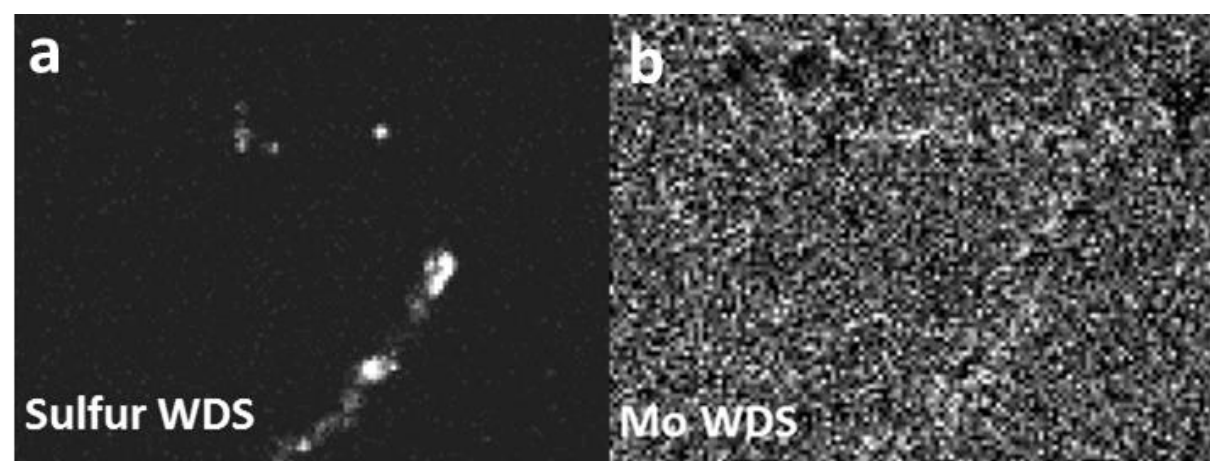

Figure 20. WDS-map showing a) Sulfur and b) Molybdenum.

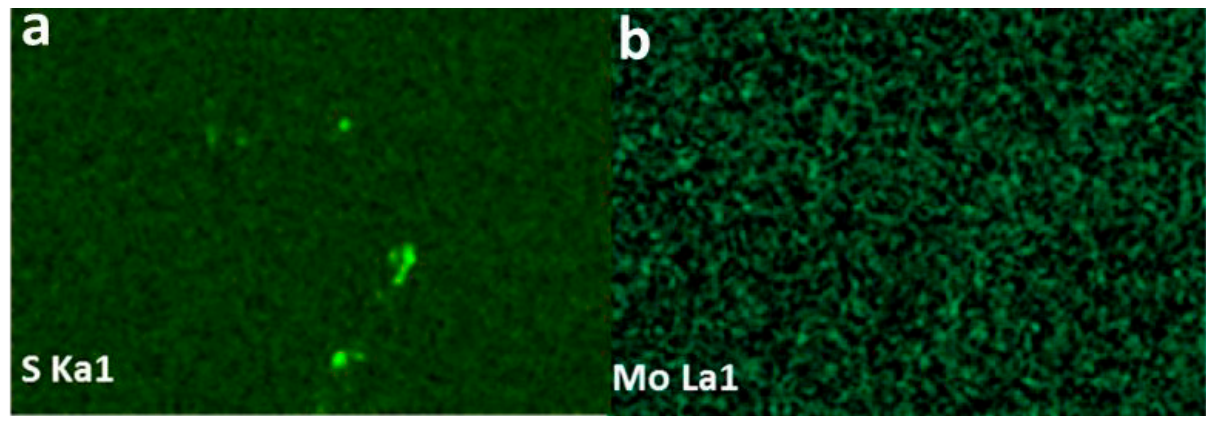

Figure 21. EDS-TruMap showing a) Sulfur and b) Molybdenum. 


\section{Summary of appended papers}

\section{Paper I}

\section{Deformation and damage mechanisms in IN792 during thermomechanical fatigue}

This paper studies deformation and damage mechanisms in cast polycrystalline IN792 during thermomechanical fatigue (TMF). In this study, in-phase (IP) and out-of-phase (OP) cycles have been used. In the both IP and OP TMF tests, the minimum temperature is $100^{\circ} \mathrm{C}$ while maximum temperatures for the IP tests are 500 or $750^{\circ} \mathrm{C}$ and for the OP test are 750,850 or $950^{\circ} \mathrm{C}$. In both IP and OP test, all cracks have initiated and propagated further in areas where dislocation structures or substructures and deformation bands has been formed. The majority of the cracks have propagated in transcrystalline mode except for IP test $750^{\circ} \mathrm{C}$ where some of the cracks have propagated in an intercrystalline manner. Formation of twins has occurred near and in front of cracks, and especially for IP test at $750^{\circ} \mathrm{C}$ and for OP test within the temperature interval 750 to $850^{\circ} \mathrm{C}$. The dislocation structures or substructures, deformation bands, twins and crack growth in areas where the material is heavily plastically deformed is visible in figure 22 . In case of IP test at $500^{\circ} \mathrm{C}$ and OP test $950^{\circ} \mathrm{C}$ formation of twins is rarer and only a few twins are formed. Recrystallization has occurred at grain boundaries and around particles at temperature interval 850 to $950^{\circ} \mathrm{C}$ for the $\mathrm{OP}$ test. However, for the temperature $950^{\circ} \mathrm{C}$ recrystallization has also occurred in an area where the material is heavily plastically deformed where also voids are frequently observed.

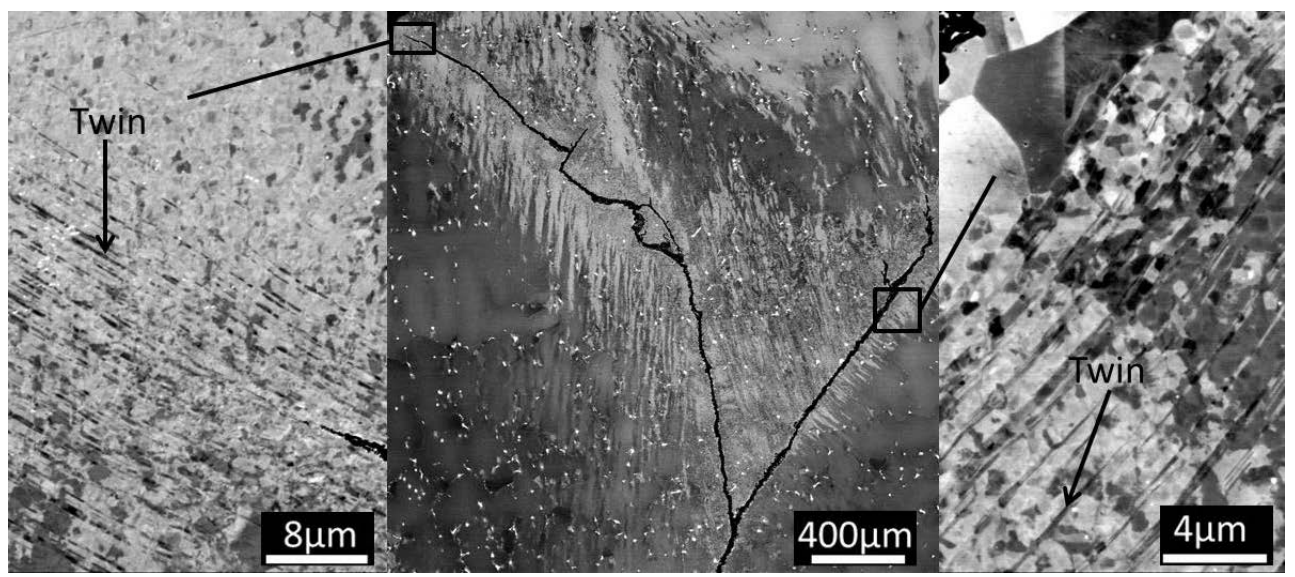

Figure 22. ECCI showing transcrystalline crack propagation in the area where the material is heavily plastically deformed. Left and right close-up show establishment of twins in front of crack and in the surrounding of the crack. 


\section{Paper II}

\section{Hot corrosion influence on deformation and damage mechanisms in turbine blades made of IN-792 during service}

This paper is focusing on studies of deformation and damage mechanisms in two turbine blades made of investment cast polycrystalline superalloy IN-972 during service. The engine has been placed off-shore. In this study a comparison is made to a previous study with focus on deformation and damage mechanisms in IN-792 during thermal mechanical fatigue testing performed under laboratory conditions. The two dominating damage mechanisms are a combination of mechanical and chemical damage in the turbine blade during service. The mechanical and chemical damage mechanisms are creep and type I hot corrosion. Ti-sulfides and sulfur in free form is present at the grain boundaries, which confirm type I hot corrosion. In turn, this has caused embrittlement and loss of resistance to crack growth, which has shortened the turbine blade life dramatically. Intercrystalline failure is the dominant damage mechanism and almost all cracks have propagated in an intercrystalline mode in the turbine blades. Figure 23 shows how a crack has propagated along a grain boundary where Ti-sulfides exist and in the same figure, substructures are visible. In the previous study, fatigue/cyclic mechanical damage mechanism is the dominant mechanism and for the highest temperature also oxidation contributes to damage development. In the previous study, almost all cracks propagated transcrystalline, i.e. the damage development under laboratory and engine condition is significantly different. When exposed to laboratory conditions, the areas around cracks are more plastically deformed compared to the area around the cracks in the turbine blades. In the two studies, dynamic recrystallization has occurred at the grain boundaries.



Figure 23. ECCI showing the type I hot corrosion in one of the turbine blades. There, the crack is propagating intercrystalline. The EDS true-maps for $S$ and Ti confirm formation of Ti-sulfides in the grain boundaries. 


\section{Paper III}

\section{Hot corrosion and internal corrosion influence on deformation and damage mechanisms in turbine blades made of IN-792 during service.}

This paper deals with a metallographic study of a turbine blade placed on a land based turbine in an industrial environment. The study is focused on damage mechanisms acting in the degradation of the turbine blade. The machine has been run as a land based machine with approximately 30 days between start and stop. This, in turn, has created steady-state temperature gradients around the cooling holes of the blade. The cooling holes act as cold spots on the hot surface, which at high temperature/operating condition establish a tensile stress field around the cooling holes. The tensile stress establishes a condition for creep damage, which, in turn, plastically deformed the material so substructures with twins are established near the crack. The left and right close-up in figure 22 shows the substructure from test bar exposed to TMF testing. The left part of figure 24 displays the substructure from the turbine blade used during service. The appearance of the two substructures differ significantly from each other and gives an indication that that the turbine blade is not exposed to significant thermal or mechanical fatigue. The turbine blade is rather exposed to chemical degradation by type I hot corrosion and internal corrosion/nitridation. Ti-sulfides have been formed in the grain boundaries and near the crack, which indirectly confirms type I hot corrosion. The internal corrosion/nitridation is confirmed by the of TiN and AlN, which in turn, has formed a depletion zone in vicinity of the crack. Figure 24 shows the area just in front of the main crack and in the microstructure, formation of twins and substructure are visible. In the same figure, the formation of a depletion zone is visible. Within the depletion zone many black particles are visible, which is TiN.

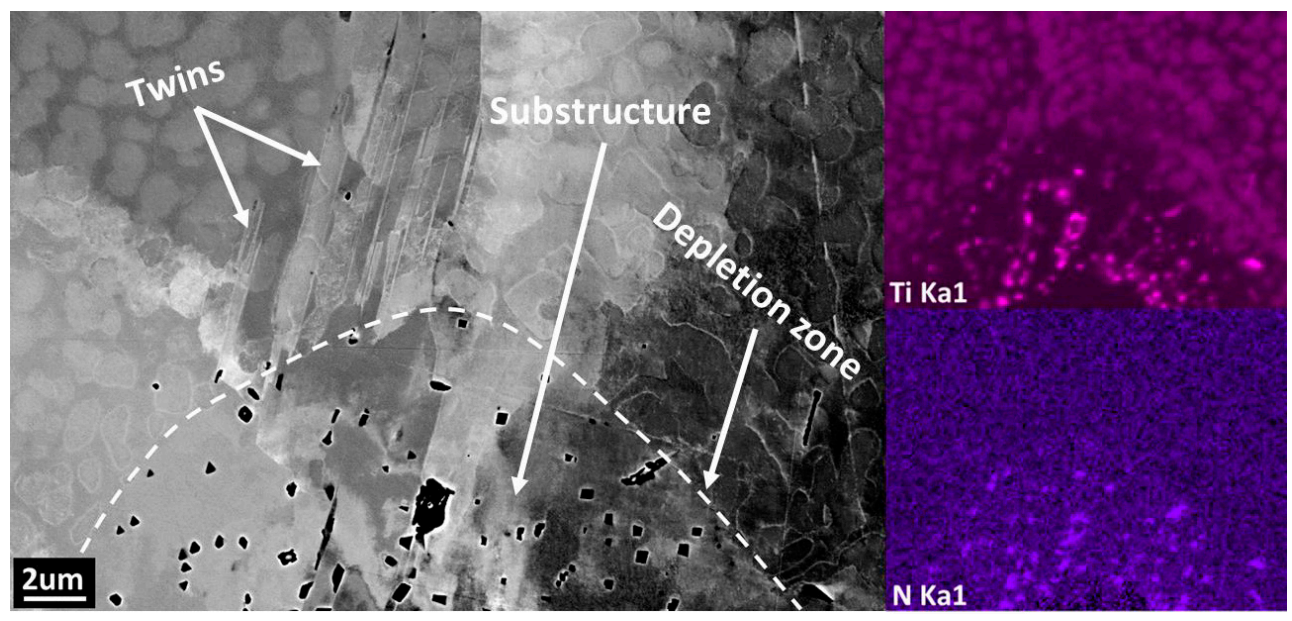

Figure 24. ECCI showing a depletion zone in front of the crack with formation of twins and substructures. Many of the black particles within the depletion zone is TiN and the formation of them is confirmed by the Ti and N EDS true-maps. 


\section{Conclusion}

The present study includes results from a SEM characterization of deformation and damage mechanisms. Results from test bars exposed to thermomechanical fatigue in laboratory environment and gas turbine blades from two gas turbine engines operating under different service condition have been presented. One of the machines is placed off shore and the components are exposed to a marine environment. The other machine is land-based and the components are exposed to an industrial environment. The test bars and the turbine blades are made of IN-792, which is a cast polycrystalline superalloy. The deformation mechanism such as formation of deformation structures (substructures) and formation of twins is observed in both the test bars and the turbine blades. The substructures differ in appearance between the test bars exposed to TMF-testing and the turbine blades, which give an indication that turbine blades are not exposed to significant thermal or mechanical fatigue. Test bars are typically more plastically deformed at cracks and the surrounding area compared to turbine blades. Dynamic recrystallization has occurred in the grain boundaries for the test bar and the gas turbine engine placed off shore. Both of the two gas turbine engines are exposed to type I hot corrosion and the gas turbine placed off shore is heavily attacked by this chemical damage mechanism. The land-based gas turbine engine is exposed to lesser damage of type I hot corrosion, however, instead the gas turbine show signs of internal corrosion/nitridation. The process includes in type I hot corrosion involves that sulfur has penetrated into and deep beyond the grain boundaries. Sulfur is extremely deleterious in the grain boundaries by causing embrittlement, which lead to an extreme shortening of the component life. The internal nitridation dissolves the $\gamma^{\prime}$ and establish a depletion zone in front of the crack tip and surroundings area, which, in turn, will affect the crack propagation and crack rate. The chemical degradation influences the component life extensively and must not be disregarded in setting up testing conditions to get satisfactory results. 


\section{Outlook}

The results from this work indicate that testing in a laboratory environment is not sufficient to accurately describe fatigue degradation under service conditions in a gas turbine. This is due to the fact that testing is not performed in an aggressive environment, such as in the case of a gas turbine hot section. The aggressive environment created during service will result in chemical degradation which, in turn, will dramatically decrease the life of the component. Further experimental work is needed to create a more service-like environmental condition like in a running gas turbine as a replacement for or addition to present thermomechanical fatigue or creep testing. To take into account the chemical degradation processes not only experiments with aggressive environment is needed but also subsequent extensive studies of the microstructural development under service conditions. In order to capture the correct degradation mechanisms, it is extremely important to get a clear coupling to real service conditions in future experiments. 


\section{References}

[1] T. Giampaola, Gas Turbine handbook: principles and practice fourth ed. The Fairmont Press, 2009.

[2] C.T. Sims, N.S. Stoloff, and W. C. Hagel, Superalloys II. Wiley Interscience, 1987.

[3] O. Singh, Applied Thermodynamics third ed. New Age International (P) Ltd, 2009.

[4] S. Bose, High temperature Coatings. Butterworth-Heinemann, 2007.

[5] R.C. Reed, The Superalloys: Fundamentals and Applications, Cambridge University Press, Cambridge, UK, 2006

[6] N. Eliaz, G. Shemesh, R.M. Latanision, Eng. Fail. Anal. 9 (2002) 31-43.

[7] H. L Bernstein, R.L McAlpin, Corrosion of Industrial Gas Turbines, Corrosion: Environments and Industries Vol. 13 ASM International, Materials Park (2006)

[8] G. Y. Lai, High Temperature Corrosion and Materials Application, ASM International, Materials Park, Ohio, USA, 2007.

[9] U. Krupp, H. -J Christ. Oxid. of Metal. Vol 3 (1999) 277-298.

[10] F. J Humphreys and M Hatherly, Recrystallization and Related Annealing Phenomena second ed., Elsevier Ltd, 2004

[11] B. Tian, Ch. Lind, E. Schafler, O. Paris, Mater. Sci. and Eng. A 367 (2004) 198204.

[12] M. Dahlen, L. Winberg, Acta Metall. 28 (1980) 41-50.

[13] D.R. Askland, P.P. Phulé, The Science and Engineering of Materials, fifth ed., Thomson, Toronto, 2006.

[14] E. Fleury, J. S. Ha, Mater. Sci. and Tech. Vol. 17 (2001) 1087-1092.

[15] F. Sun, J. Zhang, H Harada. Acta Mater 67 (2014) 45-57.

[16] L. Rémy, Comprehensive Structural Integrity, Vol. 5,113-199, 2003

[17] R. W. Herstberg, Deformation and Fracture Mechanics of Engineering Materials, fourth ed. Wiley, 1996.

[18] S. Suresh, Fatigue of Materials, second ed., Cambridge University Press, 2004.

[19] ASTM E606-04, Standard Practice for Strain-Controlled Fatigue Testing, 2004.

[20] P. Rodriguez, K.B.S. Rao, Prog. in Mater. Sci., Vol. 37, 403-480, 1993.

[21] M. Eskner, R. Sandström, Surf. and Coat. Tech. 165 (2003) 71-80. 
[22] S. A. Yandt, Development of a Thermal-Mechanical Fatigue Testing Facility, PhD thesis, Carleton University Ottawa, Ontario, 2000.

[23] F. C. Campbell, Elements of Metallurgy and Engineering Alloys, ASM International, Materials Park, Ohio, USA, 2008.

[24] D. Lee, I. Shin, Y. Kim, J.M. Koo, C.S. Seok, Inter. Jour. of Fat. 62 (2014) 62-66.

[25] H. U Hong, J.G. Kang, B.G. Choi, I.S. Kim, Y.S. Yoo, C.Y. Jo, Inter. Jour. of Fat. 33 (2011) 1592-1599.

[26] Z.W. Huang, Z.G. Wang, S.J. Zhu, F.H Yuan, F.G. Wang, Mater. Sci. and Eng. A 432 (2006) 308-316.

[27] A. G. d 1. Yedra, A M Meizoso, R. R. Martín, J.L. Pedrejón, Inter. Jour. of Eng. Scien. and Tech., Vol. 3, No. 6, 2011,88-101.

[28] ASTME 2368 - 04, Standard Practice for Strain Controlled Thermomechanical Fatigue Testing, 2005.

[29] F. Liu, S.H. Ai, Y.C. Wang, H. Zhang, Z.G Wang, Inter. Jour. of Fat. 24 (2002) 841846.

[30] J. Yu, G. Han, Zh. Chu, X. Sun, T. Jin, Zh. Hu, Mater. Sci. and Eng. A 592 (2014) 164172.

[31] T. Beck, G. Pitz, K.-H Lang, D. Löhe, Mater. Sci. and Eng. A 234-236 (1997) 719-722.

[32] J. Kanesund, J.J. Moverare, S. Johansson, Mater. Sci. and Eng. A 528 (2011) 46584668.

[33] M. Yoshiba, O. Miyagawa, 9 Inter. Con. on Metal. Corr., 1984

[34] E. Aghion, M. Walker, D. Eliezer, N. Comins, Jour. Of Mater. Sci. 31 (1996) 27352740.

[35] D.A. Woodford, R.H. Bricknell Scrip Metal. Vol. 17 (1983) 1341-1344.

[36] R. Viswanathan, Eng. Fail. Anal. 8 (2001) 493-511.

[37] E. Aghion, G. Govender, N. Comins, Jour. Of Mater. Sci. 30 (1995) 2163-2170.

[38] M. F. Ashby, D: R. H. Jones, Engineering Materials 1, Third ed., Elsevier ButterworthHeinemann, 2005.

[39] Dr. U. Kohl-Roscher, AsB Detector, Showing Material Contrast and Topographical Information with the AsB Detector, Carl Zeiss Microscopy GmbH, www.zeiss.com, 2003. 
[40] S. Zaefferer, N.N. Elhami, Acta Mater. 75 (2014) 20-50.

[41] Z.F. Zhang, Z.G. Wang, Z.M. Sun, Acta Mater. 49 (2001) 2875-2886.

[42] I. Gutierrez-Urrutia,S. Zaefferer, D. Raabe, Scrip Mater 61 (2009) 737-740.

[43] EBSD Explained, Oxford Instrument plc, www.oxford-instruments.com, 2015.

[44] J. I. Goldstein, D, Newbury, D. Joy, Ch. Lyman, P. Echlin, E. Lifshin, L. Sawyer, J. Michael, Scanning Electron Microscopy and X-Ray Microanalysis third ed., 2007.

[45] P. J. Staham, Analyt. Chem. Vol. 49, No. 14, 1977

[46] Tru-Q-Making Accurate Analysis a Reality for All, Oxford Instrument plc, www.oxford-instruments.com , 2011.

[47] TruMap: Real Time-Real Results, Application note, Oxford Instrument plc, www.oxford-instruments.com , 2011. 


\section{Papers}

The articles associated with this thesis have been removed for copyright reasons. For more details about these see:

http://urn.kb.se/resolve?urn=urn:nbn:se:liu:diva-133824 